\title{
Juvenile Paget disease
}

INSERM

\section{Source}

INSERM. (1999). Orphanet: an online rare disease and orphan drug data base. Juvenile Paget disease. ORPHA:2801

Juvenile Paget disease is a very rare form of Paget disease of the bone characterized by a general increase in bone turnover with increased bone resorption and deposition, resulting in cortical and trabecular thickening, and clinically presenting as progressive skeletal deformities, growth impairment, fractures, vertebral collapse, skull enlargement and sensorineural hearing loss. 